\title{
Centros históricos en México, patrimonialización global y turistificación
}

\begin{abstract}
Pablo Trujillo García 1
Resumen: El patrimonio cultural urbano de ciudades y pueblos mexicanos desde la década de 1970 se protege y valora mediante las declaratorias d e Zonas de Monumentos Históricos, una política pública para exaltar la identidad, el nacionalismo y la historia mexicana. En la década de 1980 México entró al mercado global, y priorizó el turismo y la economía. El objetivo de este artículo es mostrar cómo México pasó del culto a los monumentos a la industria patrimonial turística y a la patrimonialización global, y cómo las declaratorias disminuyeron desde 2001, con la creación del programa turístico Pueblos Mágicos, que aprovecha el patrimonio cultural urbano de las localidades para atraer turistas nacionales y extranjeros. Mediante el análisis entre las declaratorias y los nombramientos de Pueblos Mágicos entre 1970 y 2018, se demuestra que las políticas turísticas tomaron el patrimonio como un recurso económico y se descuidó su conservación.
\end{abstract}

Palabras-clave: Zonas de Monumentos; patrimonio; turismo; Pueblos Mágicos; patrimonialización global.

\section{Centros históricos no México, patrimonialização global e turística}

Resumo: A herança cultural urbana das cidades e vilas mexicanas desde a década de 1970 é protegida e valorizada pelas Declarações de Zonas de Monumentos Históricos, uma política pública para exaltar a identidade, o nacionalismo e a história mexicanos. Na década de 1980, o México entrou no mercado global, priorizando o turismo e a economia. O objetivo deste artigo é mostrar como o México passou do culto aos monumentos à indústria do patrimônio turístico e à patrimonialização global, e como as declarações diminuíram desde 2001, com a criação do programa de turismo Pueblos Mágicos, que aproveita o patrimônio cultural urbano do localidades para atrair turistas nacionais e estrangeiros. Através da análise entre as declarações e as nomeações de Pueblos Mágicos entre 1970 e 2018, mostra-se que as políticas de turismo tomaram o patrimônio como recurso econômico e sua conservação foi negligenciada. Palavras-chave: Zonas de Monumentos; patrimônio; turismo; Pueblos Mágicos; patrimonialização global.

\section{Historical centers in Mexico, global patrimonialization and touristification}

\begin{abstract}
The urban cultural heritage of Mexican cities and towns since the 1970s is protected and valued through the Declarations of Zonas de Monumentos Históricos, a public policy to exalt Mexican identity, nationalism and history. In the 1980s, Mexico entered the global market, prioritizing tourism and the economy. The objective of this article is to show how Mexico went from the cult of monuments to the tourist heritage industry and global patrimonialization, and how declarations decreased since 2001, with the creation of the Pueblos Mágicos tourism program, which takes advantage of the urban cultural heritage of the localities to attract national and foreign tourists. Through the analysis between the declarations and the appointments of Pueblos Mágicos between 1970 and 2018, this shows that tourism policies in demonstrating that tourism policies took heritage as an economic resource and its conservation was neglected.
\end{abstract}

Keywords: Zonas de Monumentos; heritage; tourism; Pueblos Mágicos; global heritagization

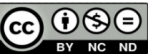

DOI: https://doi.org/10.26512/patryter.v4i7.29436

Como citar este artigo: Trujillo-García, P. (2021). Centros históricos en México, patrimonialización global y turistificación. PatryTer - Revista Latinoamericana e Caribenha de Geografia e Humanidades, 4 (7), 28-43. DOI: https://doi.org/10.26512/patryter.v4i7.29436

Recebido: 30 de janeiro de 2020. Aceite: 25 de maio de 2020. Publicado: 01 de março de 2021.

${ }^{1}$ Maestro en urbanismo y candidato a doctor en urbanismo por la Universidad Nacional Autónoma de México. ORCID: https://orcid.org/0000-0001-8334-0892. E-mail: pablotrujilloinah@yahoo.com.mx 


\section{Introducción}

Este artículo forma parte de la investigación doctoral que llevo a cabo en el Programa de Maestría y Doctorado en Urbanismo, en la Facultad de Arquitectura de la Universidad Nacional Autónoma de México. El objetivo es identificar el proceso de patrimonialización de algunas ciudades históricas mexicanas declaradas Zonas de Monumentos Históricos (en adelante ZMH) desde la década de 1970 hasta 2018, y el proceso de turistificación luego de la creación en 2001 del programa Pueblos Mágicos de la Secretaría de Turismo (en adelante Sectur); asimismo, hacer un análisis cuantitativo de los decretos de ZMH expedidos por la presidencia de la república y publicados en el Diario Oficial de la Federación (en adelante DOF). El interés en esta línea de investigación tiene el propósito de dar fundamento al trabajo empírico desarrollado desde 1991 en la Coordinación Nacional de Monumentos Históricos (en adelante CNMH) del Instituto Nacional de Antropología e Historia (en adelante INAH) donde he realizado varios estudios urbanos y arquitectónicos, y he colaborado en la elaboración de los proyectos para las declaratorias de $\mathrm{ZMH}$.

Desde su creación en 1939 el INAH es el organismo encargado por la Ley Orgánica (DOF, 1939), para proponer las declaratorias de $\mathrm{ZMH}$ al presidente de la república en turno, ${ }^{i}$ para ser publicadas en el DOF. Desde la década de 1970 hasta la fecha, la elaboración de los estudios, expedientes y proyectos de las declaratorias recae en la CNMH, a través de sus diferentes unidades encargadas del estudio de las ciudades históricas de México, con base en la Ley Federal sobre Monumentos y Zonas Arqueológicos, Artísticos e Históricos y el Reglamento de la Ley Federal (DOF, 1972). Las declaratorias inicialmente eran signadas por el presidente en turno y por los secretarios de Educación Pública, de Desarrollo Urbano y de Turismo, esto cambió en el sexenio del presidente Ernesto Zedillo (1994-2000), a partir de entonces se prescindió de la firma de la Sectur; sugiriendo sus propias consideraciones económicas respecto del patrimonio cultural urbano, como lo define Díaz-Berrio (2007), como se verá más adelante.

A lo largo de ocho sexenios, de 1970 a 2018, se publicaron 59 declaratorias de ZMH más dos Listados de Monumentos Históricos (Tabla 1). La protección y conservación de las ZMH tiene su base legal en la Constitución Política de los Estados Unidos Mexicanos y desde la década de 1970 involucra varias leyes, principalmente la Ley
Federal de 1972, y su reglamento de 1975; la Ley General de Asentamientos Humanos y Ordenamiento Territorial, que data de 1976 (actualizada varias veces, la más reciente en 2016) (DOF, 2016); y la Ley Federal de Fomento al Turismo de 1974 (derogada en 2009 por la actual Ley General de Turismo) (Sectur, 2009). Estas tres leyes concurren directamente en el patrimonio cultural urbano; la primera, enfatiza sobre su investigación, protección, conservación, recuperación y difusión; la segunda, considera el desarrollo urbano de los centros de población, incluyendo preservar sus valores históricos y culturales; y la tercera, busca el aprovechamiento de ese patrimonio cultural como recurso turístico y motor del desarrollo de la economía nacional.

Una declaratoria es el instrumento legal indispensable para la protección y conservación del patrimonio cultural urbano de la nación, que involucra a la Secretaría de Cultura, a la Secretaría de Desarrollo Agrario, Territorial y Urbano y a la Sectur, cada una con objetivos, intereses, normatividad y competencias distintas. Las ZMH son entes vivos que cambian continuamente e involucran intereses y presiones por el desarrollo urbano e inmobiliario, la economía y el turismo; ello dificulta una gestión integral que permita su tutela para evitar la pérdida o alteración de sus valores históricos y culturales para trasmitirlos a las generaciones futuras.

Desde la segunda mitad del siglo XX el turismo es una de las actividades que más empleos han generado en México, actualmente representa el $8.2 \%$ del Producto Interno Bruto. De acuerdo con la Organización Mundial de Turismo (OMT), México es el segundo país del continente americano y el sexto del mundo más visitado por turistas internacionales, con 39.3 millones en 2018 (Sectur, 2018), y de acuerdo con la Organización de la Naciones Unidas para la Educación, la Ciencia y la Cultura (en adelante Unesco), México forma parte de la patrimonialización global, concepto acuñado por Costa (2014, pp. 241-256) para referirse a la universalización de lugares o sectores de ciudades en el contexto de una urbanización de nuevas dimensiones del patrimonio, pues es el país del continente americano con el mayor número de sitios inscritos en la Lista del Patrimonio Mundial, y el sexto del mundo, con 35 sitios, entre culturales, naturales y mixtos (Conaculta-INAH, 2009); además, cuenta con 11 inscripciones en la Lista Representativa de Patrimonio Cultural Inmaterial de la Humanidad de la Unesco.

Desde 1972 la Lista del Patrimonio Mundial de la Unesco ha generado prácticas "sustentables" de conservación del patrimonio, que 
han turistificado y mercantilizado el patrimonio natural y cultural del mundo, parafraseando a Delgadillo (2015): el éxito de estas prácticas se sustenta básicamente porque se dice apolítica ante las amenazas homogeneizadoras globales, cuando paradójicamente aplica criterios universales y de valor excepcional, incluye lugares preferidos por el turismo cultural urbano que cada vez es más, y consume sitios urbanos con valor patrimonial; no obstante, es una actividad lucrativa y generadora de recursos económicos que no necesariamente se invierten en la conservación ni en las comunidades que lo ostentan. Así, el turismo irrumpe en ciudades con características urbanas no concebidas para tal actividad, que de no ser controlado podría producir impactos negativos en el patrimonio edificado y podría convertirse en un agente gentrificador, pues el turístico es un uso que puede pagar más que otros usos del suelo. El turismo cultural se ha constituido en "una función urbana emergente" capaz de sustentar, en su más amplia expresión, la recuperación funcional y física de los Centros históricos; en este sentido, el concepto turistificación se relaciona con la globalización y con el neoliberalismo:

\begin{abstract}
El turismo global no es una industria sin chimeneas, sino una actividad económica que busca el lucro y que profundiza las desigualdades socioeconómicas. La turistificación del patrimonio urbano que vende productos únicos, diferentes, auténticos y universalmente excepcionales a su manera puede conducir a la parquetematización, museificación, disneyficación, boutiquización y gentrificación de esa herencia edificada porque esta actividad privilegia los servicios para los clientes foráneos. Aqui, las inversiones públicas y privadas tienden a homogeneizar globalmente estos territorios locales por la paulatina estandarización de los servicios turísticos globales, la instalación de marcas globales y cadenas de hoteles, de tiendas, de restaurantes y de lugares de comida rápida, etcétera (Delgadillo, 2015, pp. 115-132).
\end{abstract}

La relación y problemática entre patrimonio y turismo ha sido tratada por varios autores como, Françoise Choay, quien en su libro Alegoría del Patrimonio aborda, entre varios aspectos, cómo se pasó del culto a los monumentos a la industria patrimonial, donde los Centros históricos pasaron a ser un producto de consumo cultural; también, considera las afectaciones que suceden al acondicionarlos para ser visitados por los turistas, convirtiéndolos en un escenario museal, y cómo estas prácticas, ya sea como culto o como industria, amenazan con su autodestrucción (Choay, 2007).
En el ámbito latinoamericano, y desde la geografía, Everaldo Costa aborda esta problemática en su tesis doctoral y en el artículo Fundamentos de uma emergente patrimonialização global destaca que estos lugares alcanzan su punto máximo al ser distinguidos con el sello de Patrimonio Mundial, e invariablemente transforman su esencia, autenticidad, originalidad e irrevocabilidad buscada o producida por los agentes y aspectos hegemónicos del turismo (Costa, 2014, pp. 241256).

\section{Las Zonas de Monumentos Históricos, ¿un reconocimiento al patrimonio cultural urbano nacional?}

La conservación de los Centros históricos surgió con las teorías e ideas sobre la identidad nacional y el simbolismo del patrimonio cultural urbano, que a mediados del siglo XIX y principios del XX (Bandarin y Van Oers, 2014) permearon el espíritu de la legislación mexicana, por lo que se emitieron decretos y leyes que privilegiaron la investigación, protección, conservación, restauración, recuperación y difusión de este patrimonio cultural urbano (Díaz-Berrio, 2007, pp. 20-55). Primero, en 1934 se creó la figura de Zona Típica y Pintoresca, posteriormente en 1972 la de ZMH, como una política del Estado mexicano basada en la utilidad pública y el uso social del patrimonio cultural de la nación, especialmente de los monumentos y las zonas de monumentos, anteponiendo el interés público sobre el interés privado (DOF, 1972).

El caso del Estado mexicano se considera en América Latina vanguardista en materia legal para la protección de su patrimonio cultural, aunque estuvo sumamente influenciado por la legislación francesa, especialmente por la Ley de monumentos históricos del 2 de mayo de 1930, esta ley menciona el concepto "interés público o interés nacional", para definir el bien común de la sociedad y no sólo el interés del Estado en sí mismo en la protección de dichos bienes; también, menciona el "valor histórico o artístico" que igualmente retomaron las leyes mexicanas, a saber las siguientes:

- Ley sobre Conservación de Monumentos Históricos, Artísticos y Bellezas Naturales, del 6 de abril de 1914.

- Ley sobre Protección y Conservación de Monumentos y Bellezas Naturales, del 31 de enero de 1930. 
- Ley sobre Protección y Conservación de Monumentos Arqueológicos e Históricos, Poblaciones Típicas y Lugares de Belleza Natural, del 19 de enero de 1934.

- Ley Federal de Patrimonio Cultural de la Nación, del 23 de diciembre de 1968.

- Ley Federal sobre Monumentos y Zonas Arqueológicos, Artísticos e Históricos, del 6 de mayo de 1972.

De acuerdo con el artículo 41 de la Ley Federal sobre Monumentos y Zonas Arqueológicos, Artísticos e Históricos: Zona de monumentos históricos es el área que comprende varios monumentos históricos relacionados con un suceso nacional o la que se encuentre vinculada a bechos pretéritos de relevancia para el país.

Es preciso señalar que las declaratorias de $\mathrm{ZMH}$ no las emite el INAH, de acuerdo con la legislación vigente al día de hoy, el instituto las propone al presidente de la república en turno, quien las expide, otorgando así el rango de interés nacional a su conservación integral. La Ley Federal atendió la patrimonialización; es decir, la puesta en valor de los Centros históricos mexicanos. Al respecto es pertinente referir a Frgolé (2014) quien menciona "La patrimonialización convierte una porción de territorio en área protegida y un edifico en monumento"; por ello, se advierte que al emitir las declaratorias, el Estado mexicano no solamente revalora una parte del territorio de una localidad; del mismo modo, el autor también señala que la patrimonialización permite otro mecanismo "la mercantilización de lo auténtico”, y equipara la patrimonialización con la mercantilización de lo auténtico, porque el valor del pasado es la base del patrimonio, pero también de los elementos mercantilizados como auténticos (Frigolé, 2014, pp. 31-45).

En este sentido es pertinente cuestionar si se han reconocido los hechos pretéritos de relevancia para la historia mexicana, y analizar si las declaratorias de ZMH son un reconocimiento al patrimonio cultural urbano nacional, debido a que la patrimonialización en México se materializó mediante la publicación de las declaratorias en el DOF. El hecho se ha dado de la siguiente manera: en el sexenio de Luis Echeverría Álvarez (19701976) se emitió la Ley Federal en 1972, y su reglamento en 1975 y dos declaratorias de $\mathrm{ZMH}$; en el de José López Portillo (1976-1982) diez declaratorias; en el de Miguel de la Madrid Hurtado (1982-1988) 20 declaratorias; en el de Carlos Salinas de Gortari (1988-1994) nueve declaratorias, más dos Listados de Monumentos Históricos;ii en el de Ernesto Zedillo Ponce de León (1994-2000) seis declaratorias; en el de Vicente Fox Quesada (2000-2006) diez declaratorias; en el de Felipe Calderón Hinojosa (2006-2012) dos declaratorias; y en el de Enrique Peña Nieto (2006-2018) ninguna declaratoria. Durante ocho sexenios, de 1970 a 2018 (48 años), en total se publicaron 59 Decretos de ZMHiii (Tabla 1, Mapa 1).

Figura 1 - ZMH declaradas por sexenio y Listados de Monumentos Históricos, en orden de publicación en el DOF

\begin{tabular}{|c|c|c|}
\hline Luis Echeverría Álvarez & (1970-1976) & Publicación DOF \\
\hline & Ixcateopan, Guerrero & $28 / 03 / 75$ \\
\hline & Oaxaca de Juárez, Oaxaca & $19 / 03 / 76$ \\
\hline \multirow[t]{11}{*}{ José López Portillo } & $(1976-1982)$ & Publicación DOF \\
\hline & Puebla de Zaragoza, Puebla & $18 / 11 / 77$ \\
\hline & Ayoxuxtla de Zapata, Puebla & $04 / 12 / 79$ \\
\hline & Centro Histórico de la Ciudad de México, Cdmx. & $11 / 04 / 80$ \\
\hline & Querétaro de Arteaga, Querétaro & $30 / 03 / 81$ \\
\hline & Dolores Hidalgo, Guanajuato & $27 / 07 / 82$ \\
\hline & Pozos, Guanajuato & $27 / 07 / 82$ \\
\hline & Guanajuato, Guanajuato & $28 / 07 / 82$ \\
\hline & San Miguel de Allende, Guanajuato & $28 / 07 / 82$ \\
\hline & Durango, Durango & $13 / 08 / 82$ \\
\hline & Mérida, Yucatán & $18 / 10 / 82$ \\
\hline \multirow[t]{13}{*}{ Miguel de la Madrid Hurtado } & $(1982-1988)$ & Publicación DOF \\
\hline & San Luis Huamantla, Tlaxcala & $12 / 11 / 84$ \\
\hline & Orizaba, Veracruz & $25 / 01 / 85$ \\
\hline & San Felipe Ixtacuixtla, Tlaxcala & $01 / 04 / 86$ \\
\hline & San Antonio Calpulalpan, Tlaxcala & $03 / 04 / 86$ \\
\hline & San Pablo Apetatitlan, Tlaxcala & $04 / 04 / 86$ \\
\hline & Tlaxco de Morelos, Tlaxcala & $09 / 04 / 86$ \\
\hline & Tlaxcala de Xicoténcatl, Tlaxcala & $11 / 04 / 86$ \\
\hline & San Pedro y San Pablo Teposcolula, Oaxaca & $11 / 08 / 86$ \\
\hline & San Juan del Río, Querétaro & $03 / 12 / 86$ \\
\hline & San Cristóbal de las Casas, Chiapas & $04 / 12 / 86$ \\
\hline & Xochimilco, Tláhuac y Milpa Alta, Cdmx. & $04 / 12 / 86$ \\
\hline & Santa Rosalía, Baja California Sur & $05 / 12 / 86$ \\
\hline
\end{tabular}

PatryTer | ISSN: 2595-0169 | vol. 4 | n. 7 | março 2021 | pp. 28-43 | Artigo 


\begin{tabular}{|c|c|c|}
\hline & Tlalpan, Cdmx. & $05 / 12 / 86$ \\
\hline & Mexcaltitán de Uribe, Nayarit & $08 / 12 / 86$ \\
\hline & Azcapotzalco, Cdmx. & $09 / 12 / 86$ \\
\hline & Campeche, Campeche & $10 / 12 / 86$ \\
\hline & Tlacotalpan, Veracruz & $10 / 12 / 86$ \\
\hline & Villa Álvaro Obregón, Cdmx. & $11 / 12 / 86$ \\
\hline & Atlixco, Puebla & $27 / 05 / 88$ \\
\hline & Comala, Colima & $30 / 11 / 88$ \\
\hline \multirow[t]{12}{*}{ Carlos Salinas de Gortari } & $(1988-1994)$ & Publicación DOF \\
\hline & Lagos de Moreno, Jalisco & $08 / 12 / 89$ \\
\hline & Taxco de Alarcón, Guerrero & $19 / 03 / 90$ \\
\hline & Aguascalientes, Aguascalientes & $19 / 12 / 90$ \\
\hline & Córdoba, Veracruz & $19 / 12 / 90$ \\
\hline & Coyoacán, Cdmx. & $19 / 12 / 90$ \\
\hline & Morelia, Michoacán & $19 / 12 / 90$ \\
\hline & Pátzcuaro, Michoacán & $19 / 12 / 90$ \\
\hline & San Luis Potosí, San Luis Potosí & $19 / 12 / 90$ \\
\hline & Xalapa de Enríquez, Veracruz & $19 / 12 / 90$ \\
\hline & Texcoco de Mora, México* & $19 / 12 / 90$ \\
\hline & Tlayacapan, Morelos* & $19 / 12 / 90$ \\
\hline \multirow[t]{7}{*}{ Ernesto Zedillo Ponce de León } & $(1994-2000)$ & Publicación DOF \\
\hline & Parras de la Fuente, Coahuila & $18 / 02 / 98$ \\
\hline & Álamos, Sonora & $24 / 11 / 00$ \\
\hline & Chiapa de Corzo, Chiapas & $24 / 11 / 00$ \\
\hline & Coatepec, Veracruz & $24 / 11 / 00$ \\
\hline & Comitán de Domínguez, Chiapas & $24 / 11 / 00$ \\
\hline & Cosalá, Sinaloa & $24 / 11 / 00$ \\
\hline \multirow[t]{11}{*}{ Vicente Fox Quesada } & $(2000-2006)$ & Publicación DOF \\
\hline & El Albarradón de San Cristóbal, México & $09 / 03 / 01$ \\
\hline & Santa Clara del Cobre, Michoacán & $09 / 03 / 01$ \\
\hline & Valle de Allende, Chihuahua & $09 / 03 / 01$ \\
\hline & Hidalgo del Parral, Chihuahua & $12 / 03 / 01$ \\
\hline & Huexotla, México & $12 / 03 / 01$ \\
\hline & Mazatlán, Sinaloa & $12 / 03 / 01$ \\
\hline & Acuitzio del Canje, Michoacán & $20 / 03 / 01$ \\
\hline & San Miguel el Alto, Jalisco & $30 / 03 / 01$ \\
\hline & Tlalpujahua de Rayón, Michoacán & $30 / 03 / 01$ \\
\hline & Veracruz, Veracruz & $01 / 03 / 04$ \\
\hline \multirow[t]{3}{*}{ Felipe Calderón Hinojosa } & $(2006-2012)$ & Publicación DOF \\
\hline & Cuautla, Morelos & $29 / 11 / 12$ \\
\hline & Real de Catorce, San Luis Potosí & $29 / 11 / 12$ \\
\hline \multirow[t]{2}{*}{ Enrique Peña Nieto } & $(2012-2018)$ & Publicación DOF \\
\hline & $-0-$ & $-0-$ \\
\hline Total & ZMH 59+2 & \\
\hline
\end{tabular}

Fuente: Elaboración propia con base en los decretos publicados en el DOF de cada ZMH. 2018.

La turistificación de las ZMH se materializó en el sexenio de Miguel de la Madrid Hurtado (1982-1988), como presidente expidió 20 declaratorias publicadas en el DOF; en su gestión México ratificó en 1984 la Convención sobre la Protección del Patrimonio Mundial Cultural y Natural de la Unesco de 1972, debido a que el Senado de la República se oponía, por considerar que algunos de sus aspectos injerían en asuntos nacionales (Melé, 2006). La ratificación de la Convención dio como resultado que el 11 de diciembre de 1987 el Comité del Patrimonio Mundial de la Unesco inscribiera los primeros seis sitios mexicanos en la Lista del Patrimonio Mundial (Conaculta-INAH, 2009). Patrice Melé señala que la inscripción de los sitios en la Lista del Patrimonio Mundial tiene el objetivo de reconocer el valor universal de ciertos elementos del patrimonio, y para "protegerlos del peligro que los amenaza". Entre 1987 y 2008 las declaratorias federales de nueve ZMH mexicanasiv se legitimaron globalmente al incluirse exactas en la Lista del Patrimonio Mundial (Melé, 2006). Esto permitió que los Centros históricos mexicanos entraran de lleno a la patrimonialización global, concepto acuñado por Costa (2014) quien nos ofrece un enfoque teórico-metodológico para una nueva lectura de lugares resignificados que presentan una problemática semejante debido a la incursión de nuevas actividades en la economía urbana, donde impera la lógica del turismo, en el contexto de una urbanización de nuevas dimensiones del patrimonio, donde el mundo es una red internacional de turismo (Costa, 2014, pp. 241256).

En este sentido, la patrimonialización global demuestra la influencia de la Convención en los Estados parte, y los efectos que ha tenido en 
esos países, no sólo en la gestión o las políticas públicas en el ámbito nacional. Becerril (2009) señala también la influencia en el aspecto legal, en tanto tratado internacional ratificado; así, la Convención se convierte en un instrumento legal de aplicación obligatoria en el territorio nacional, que aparentemente el gobierno está dispuesto a seguir, con tal de inscribir sitios en la Lista del Patrimonio Mundial de la Unesco. Varias son las consecuencias en los espacios patrimonializados globalmente, no sólo hay mayor afluencia de visitantes, desarrollo económico o fortalecimiento de la identidad nacional o regional, sólo por mencionar algunas ventajas que sirven como argumento a los políticos para apoyar tales inscripciones; asimismo, luego de analizar la Convención el autor señala que "las medidas observadas en dicho documento parten de una visión global e integral del concepto de patrimonio cultural, alejándose de consideraciones puramente históricas o estéticas para definir este universo de bienes" (Becerril, 2009 p. 19).

Figura 2 - ZMH declaradas en la República mexicana y 2 Listados de Monumentos Históricos, en orden de publicación en el DOF de 1970 a 2018

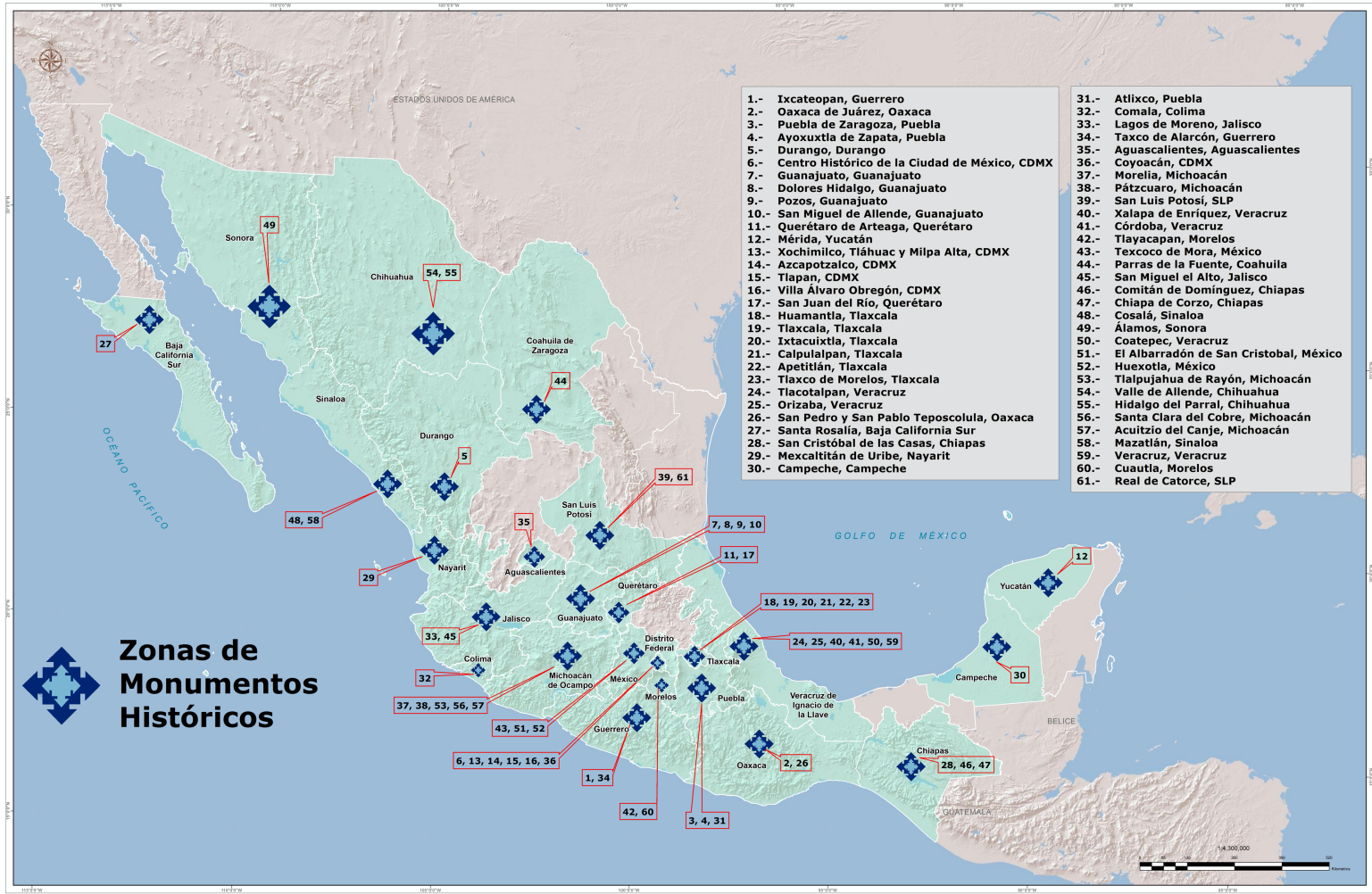

Fuente: Elaboración propia con base en los decretos publicados en el DOF de cada ZMH.

Cartografía: Mayra Ojeda, 2019

Un punto de partida para entender cómo surgió la turistificación y la patrimonialización global de los Centros históricos mexicanos, a partir de la mencionada figura legal de $\mathrm{ZMH}$, nos lo ofrece Harvey (2007), quien revela que la crisis económica en México, al final del sexenio de José López Portillo (1976-1982) y al inicio del sexenio de Miguel de la Madrid Hurtado (1982-1988), fue la causa de la inclusión de México en 1986 al Acuerdo General sobre Aranceles y Comercio (GATT por sus siglas en inglés).

Sin duda, al final de la década de 1970 México entró al mercado global y al neoliberalismo, que permeó las políticas públicas en materia de cultura y de turismo. En la década de 1980 la economía nacional se vio afectada, aumentó la inflación considerablemente, el tipo de cambio respecto del dólar se duplicó, al parecer no había otra salida que abrirse a los mercados internacionales. Pese a todo lo anterior o, en consecuencia, en el sexenio de Miguel de la Madrid Hurtado (1982-1988) 20 Centros históricos fueron declarados como $\mathrm{ZMH}$, seis en el estado de Tlaxcala, cuatro en la Ciudad de México, dos en el estado de Veracruz y ocho más en los estados de Baja California Sur, Campeche, Chiapas, Colima, Nayarit, Oaxaca, Puebla y Querétaro, con una declaratoria en cada estado (Tabla 1).

En el sexenio de Carlos Salinas de Gortari (1988-1994), el gobierno mexicano firmó acuerdos 
con el Fondo Monetario Internacional (FMI) y aceptó recomendaciones en políticas públicas a cambio de deuda externa. Paulatinamente las decisiones económicas del gobierno se fueron vinculando a los criterios de organismos internacionales como el Banco Mundial, la Organización Mundial de Comercio (OMC) y de acuerdos como el Tratado de Libre Comercio de América del Norte (TLCAN); asimismo, se emitió la Ley Federal de Procedimiento Administrativo (DOF, 1994) y la Ley Federal de Mejora Regulatoria, con la intención de implementar políticas públicas para simplificar las regulaciones, trámites y servicios, lo cual repercutió en la emisión de declaratorias.

En el sexenio de Ernesto Zedillo Ponce de León (1994-2000), se prescindió de la firma del titular de la Sectur en las declaratorias de $\mathrm{ZMH}$; además, por las leyes recientemente emitidas, los proyectos de decreto requerían realizar una consulta ciudadana y recabar las opiniones de los gobiernos locales, como parte de un proyecto de Manifestación de Impacto Regulatorio (MIR) (DOF, 2018). Definitivamente los proyectos de declaratoria se detuvieron y hubo que adecuarlos a los nuevos requisitos legales, afectando y postergando la publicación de nuevos decretos.

Durante el sexenio de Vicente Fox Quesada (2000-2006), la protección y conservación del patrimonio cultural urbano de México dio un giro hacia el turismo, su comercialización y aprovechamiento económico; sobre todo, fue más notorio porque la misma Sectur creó e implementó en 2001 el programa Pueblos Mágicos, una política pública del Estado que afianzó la turistificación del patrimonio cultural urbano mexicano al considerarlo un recurso turístico (Madrid, 2016, pp. 45-66), cuyo “éxito" llevó a la gentrificación en localidades pequeñas cuyo patrimonio cultural urbano se puso en el mapa turístico del país. Se trata de un modelo enfatizado en fomentar la inversión para aprovechar los recursos y atractivos culturales y naturales; indudablemente, se trata de un planteamiento inspirado en el capítulo dedicado a los "Pueblos históricos" del libro El impacto de la urbanización en los Centros Históricos de Iberoamérica, que reconoce los valores históricos y culturales de asentamientos humanos que han perdido vigencia; no obstante, que sus habitantes conservan las tradiciones locales (Hardoy y Gutman, 1992, pp. 279-297).

En el sexenio de Felipe Calderón (20062012), el programa Pueblos Mágicos se consolidó y solamente se emitieron dos declaratorias de ZMH. En el siguiente sexenio, de Enrique Peña Nieto (2012-2018), último del periodo de este estudio, se afianzó el programa con los últimos nombramientos de Pueblos Mágicos; sin embargo, no se emitió ninguna declaratoria.

Para finalizar y respondiendo a la pregunta planteada al inico de este apartado clas declaratorias de $\mathrm{ZMH}$ son un reconocimiento al patrimonio cultural urbano nacional? podemos decir que legalmente $y$ en estricto sentido, sí son un reconocimiento a los monumentos históricos, al patrimonio cultural urbano y a los hechos pretéritos de relevancia para la historia nacional; no obstante, la implantación del neoliberalismo, el turismo y la globaliación han marcado una profunda huella socio espacial en los Centros históricos mexicanos declarados como ZMH.

\section{El programa Pueblos Mágicos y la patrimonialización global}

El potencial turístico de las ZMH dio lugar a la creación del programa Ciudades Coloniales y Centros Urbanos instituido por la Sectur en la década de 1990 (Ortiz, 1994, pp. 18-39), para diversificar la oferta turística mexicana y aprovechar el patrimonio cultural, especialmente enfocado en los Centros históricos mexicanos inscritos en la Lista del Patrimonio Mundial de la Unesco. El patrimonio globalizado atrae a los visitantes, nacionales y extranjeros, motivados por conocer un sitio consagrado por la Unesco. La patrimonialización global, alcanza un punto álgido en la estrategia de mercado; los lugares de la lista transforman su esencia, autenticidad y originalidad, se produce y reproduce por las necesidades impuestas para satisfacer a los turistas. Desafortunadamente los sitios de la patrimonialización global se vinculan más con estrategias de marketing que con la conservación y protección de su patrimonio cultural urbano. Además, esto enfatiza la patrimonialización global como un proceso de sectorización, donde se puede intervenir de manera diferenciada en un mismo territorio urbano e impera la planificación guiada por la economía global y la tercerización de los usos del suelo derivada de los servicios turísticos (Costa, 2014).

El programa Pueblos Mágicos fue creado para aprovechar el patrimonio cultural como recurso turístico para generar una mayor derrama económica en el país, así lo estableció el Plan Nacional de Desarrollo (DOF, 2013) del gobierno de la república en el sexenio de Enrique Peña Nieto (2012-2018), por lo que se consolidó en las dos primeras décadas del siglo XXI; sin embargo, se instituyó legalmente con la publicación del 
Acuerdo que establece los lineamientos generales para la incorporación y permanencia al Programa Pueblos Mágicos en el DOF el 26 de septiembre de 2014 (DOF, 2014).

Entre las consideraciones y motivación del programa destaca el interés de la Sectur para mantener Pueblos Mágicos:

...como una marca distintiva del turismo en México, como valor agregado de la oferta turística de nuestro país y del aprovechamiento de su potencial turístico, con lo cual se genere mayor derrama económica y bienestar social, así como la preservación de la identidad de cada pueblo. Asimismo, establece la definición de Pueblo Mágico: ...es una Localidad que a través del tiempo y ante la modernidad, ha conservado su valor y berencia bistórica cultural y la manifiesta en diversas expresiones a través de su patrimonio tangible e intangible irremplazable y que cumple con los requisitos de permanencia.

El procedimiento para lograr un nombramiento resultaba mucho más sencillo que alcanzar una declaratoria; además, si se conseguía el nombramiento se accedía a recursos federales para dedicarlos a mejoras en imagen urbana y otros proyectos para atraer turistas. Varias localidades que estaban en proceso de ser declaradas $\mathrm{ZMH}$ optaron por solicitar el nombramiento, dejando para otro momento la gestión de la declaratoria y varias obtuvieron el nombramiento de Pueblo Mágico; asimismo, otras más que ya contaban con la declaratoria también buscaron y consiguieron el nombramiento.

De acuerdo con el decreto de 2014 la Sectur se encarga del programa y está facultada para otorgar el nombramiento de Pueblo Mágico, ${ }^{v}$ constituida como Grupo de Evaluación vi cuyo presidente es el titular de dicha secretaría, este grupo determina si procede o no otorgar el nombramiento de Pueblo Mágico. Los nombramientos se basan en las solicitudes enviadas por los ayuntamientos interesados en obtenerlo, éstos entregan los documentos y expedientes técnicos establecidos en la convocatoria correspondiente. El Grupo de Evaluación y Seguimiento de Pueblos Mágicos está integrado por varias entidades y organismos, entre ellos el INAH, vii es coordinado por el titular de la Sectur, y tiene, entre otras atribuciones, la facultad de emitir la recomendación para mantener o revocar el nombramiento de Pueblo Mágico.

El programa quedó fuera del presupuesto desde 2019, pues en diciembre de 2018 el secretario de Turismo del sexenio actual (20182024) confirmó la desaparición del Programa de Desarrollo Regional Sustentable y Pueblos Mágicos (Prodemagico), y argumentó: “...la federación pretende que las entidades y municipios denominados Pueblos Mágicos inviertan recursos en su propia estructura $y$ promoción" (El Universal, 2018).

Desde 2001 y hasta antes del Acuerdo de 2014 había 83 nombramientos de Pueblos Mágicos, después de la publicación y hasta 2018, suman ya 121 nombramientos. En el sexenio de Vicente Fox Quesada (2000-2006), la Sectur otorgó 26 nombramientos de Pueblos Mágicos, en el sexenio de Felipe Calderón Hinojosa (2006-2012), 57, y en el de Enrique Peña Nieto (2012-2018), 38. Entre 2001 y 2018 se otorgó un total de 121 nombramientos de Pueblos Mágicos; sin embargo, los nombramientos incluyen 22 localidades con declaratoria y otras 32 con proyecto de declaratoria (Tablas 2 y 3), quedando de la siguiente manera:

1. $22 \mathrm{ZMH}$ declaradas previamente recibieron el nombramiento de Pueblos Mágicos (Tabla 2, Mapa 2).

2. 32 Pueblos Mágicos cuentan con proyecto de declaratoria en espera de ser publicadas (Tabla 3).

3. Muchos Pueblos Mágicos conforman el entorno urbano de algún Monumento Histórico declarado.

Figura 3 - ZMH declaradas y con nombramiento de Pueblos Mágicos, por sexenio entre 2001 y 2018

\begin{tabular}{|l|l|l|}
\hline \multicolumn{2}{|l|}{ Vicente Fox Quesada } & $\mathbf{2 0 0 0 - 2 0 0 6}$ \\
\hline 1 & Real de Catorce, San Luis Potosí & $200 \boldsymbol{H}^{*}$ \\
\hline 2 & Dolores Hidalgo, Guanajuato & 2002 \\
\hline 3 & Comala, Colima & 2002 \\
\hline 4 & Taxco de Alarcón, Guerrero & 2002 \\
\hline 5 & Pátzcuaro, Michoacán & 2002 \\
\hline
\end{tabular}




\begin{tabular}{|l|l|l|}
\hline 6 & San Cristóbal de las Casas, Chiapas & 2003 \\
\hline 7 & Parras de la Fuente, Coahuila & 2004 \\
\hline 8 & Cosalá, Sinaloa & 2005 \\
\hline 9 & Álamos, Sonora & 2005 \\
\hline 10 & Tlalpujahua de Rayón, Michoacán & 2005 \\
\hline 11 & Coatepec, Veracruz & 2006 \\
\hline & Felipe Calderón Hinojosa & $\mathbf{2 0 0 6 - 2 0 1 2}$ \\
\hline 12 & San Luis Huamantla, Tlaxcala & 2007 \\
\hline 13 & Santa Clara del Cobre, Michoacán & 2010 \\
\hline 14 & Tlayacapan, Morelos & 2011 \\
\hline 15 & Pozos, Guanajuato & 2012 \\
\hline 16 & Lagos de Moreno, Jalisco & 2012 \\
\hline 17 & Comitán de Domínguez, Chiapas & 2012 \\
\hline 18 & Chiapa de Corzo, Chiapas & 2012 \\
\hline & Enrique Peña Nieto & $\mathbf{2 0 1 2 - 2 0 1 8}$ \\
\hline 19 & Orizaba, Veracruz & 2015 \\
\hline 20 & Tlaxco de Morelos, Tlaxcala & 2015 \\
\hline 21 & San Pedro y San Pablo Teposcolula, Oaxaca & 2015 \\
\hline 22 & Atlixco, Puebla & 2015 \\
\hline$*$ Esta localidad primero obtuvo el nombramiento y posteriormente la declaratoria & \\
\hline & & \\
\hline
\end{tabular}

Fuente: Elaboración propia con base en información de la Sectur, 2018.

Figura 4 - Ubicación en la República mexicana de las 22 ZMH declaradas, que también tienen nombramiento de Pueblo Mágico

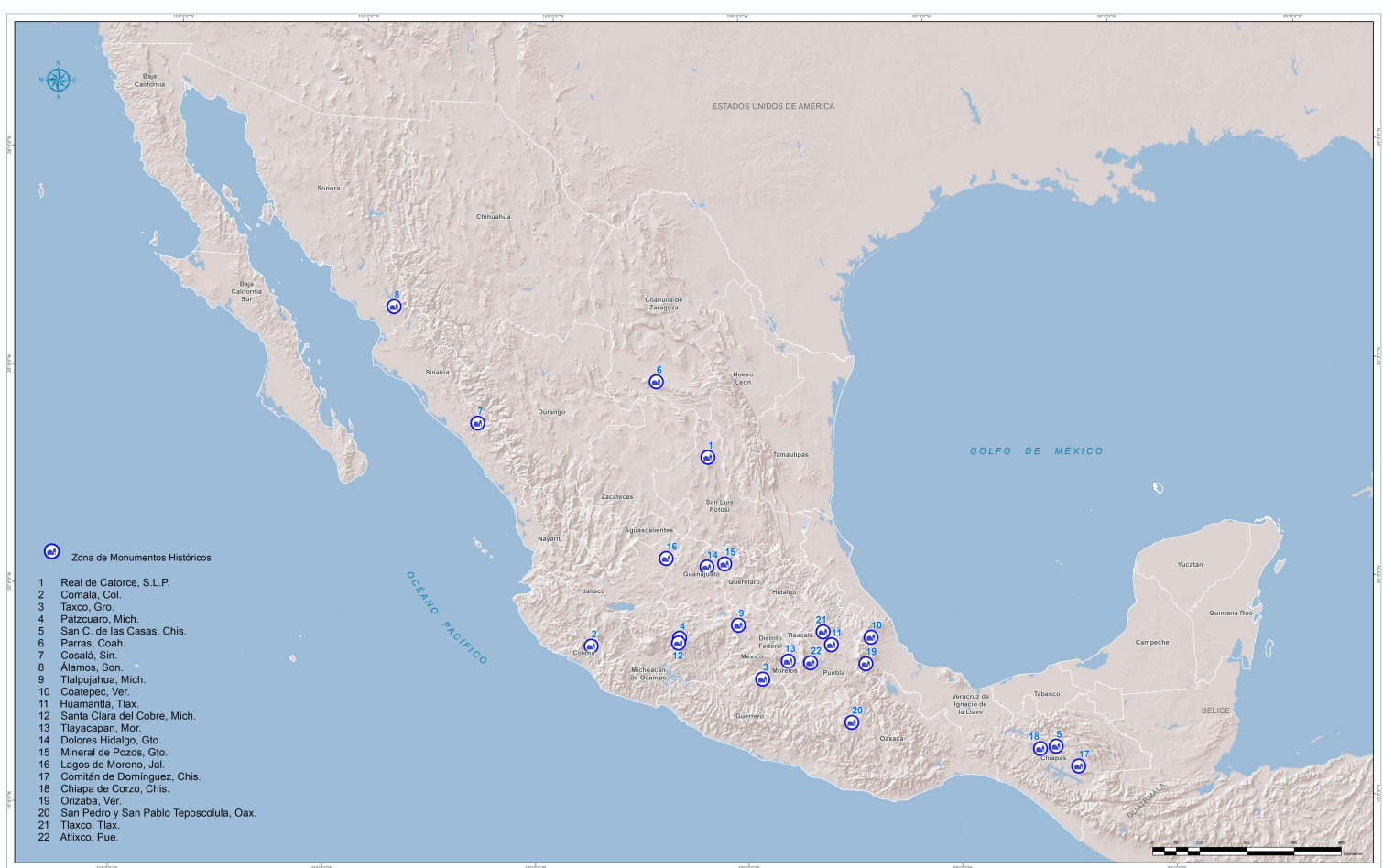

Fuente: Elaboración propia con base en los decretos publicados en el DOF de cada ZMH. Cartografía: Mayra Ojeda, 2019. 
Figura 5 - Localidades con proyecto de declaratoria de ZMH nombradas Pueblos Mágicos por sexenio

\begin{tabular}{|c|c|c|}
\hline & Vicente Fox Quesada & $2000-2006$ \\
\hline 1 & Tepoztlán, México & 2002 \\
\hline 2 & Izamal, Yucatán & 2002 \\
\hline \multirow[t]{2}{*}{3} & Real del Monte, Hidalgo & 2004 \\
\hline & Felipe Calderón Hinojosa & 2006-2012 \\
\hline 4 & Real de Asientos, Aguascalientes & 2006 \\
\hline 5 & Todos Santos, Baja California Sur & 2006 \\
\hline 6 & Cuitzeo del Porvenir, Michoacán & 2006 \\
\hline 7 & Jerez de García Salinas, Zacatecas & 2007 \\
\hline 8 & El Fuerte, Sinaloa & 2009 \\
\hline 9 & Tepoztlán, Morelos & 2010 \\
\hline 10 & Malinalco, México & 2010 \\
\hline 11 & Palizada, Campeche & 2011 \\
\hline 12 & San Sebastián del Oeste, Jalisco & 2011 \\
\hline 13 & El Oro de Hidalgo, México & 2011 \\
\hline 14 & Cadereyta de Montes, Querétaro & 2011 \\
\hline 15 & Tula, Tamaulipas & 2011 \\
\hline 16 & Xico, Veracruz & 2011 \\
\hline 17 & Loreto, Baja California Sur & 2012 \\
\hline 18 & Batopilas, Chihuahua & 2012 \\
\hline 19 & Mapimí, Durango & 2012 \\
\hline 20 & Salvatierra, Guanajuato & 2012 \\
\hline 21 & Huichapan, Hidalgo & 2012 \\
\hline 22 & Tacámbaro de Codallos, Michoacán & 2012 \\
\hline 23 & Tzintzuntzan, Michoacán & 2012 \\
\hline 24 & Mineral de Angangueo, Michoacán & 2012 \\
\hline 24 & Jala, Nayarit & 2012 \\
\hline 26 & San Pedro Cholula, Puebla & 2012 \\
\hline \multirow[t]{2}{*}{27} & Valladolid, Yucatán & 2012 \\
\hline & Enrique Peña Nieto & 2012-2018 \\
\hline 28 & Sombrerete, Zacatecas & 2012 \\
\hline 29 & Talpa de Allende, Jalisco & 2015 \\
\hline 30 & Mascota, Jalisco & 2015 \\
\hline 31 & Mocorito, Sinaloa & 2015 \\
\hline 32 & Coscomatepec, Veracruz & 2015 \\
\hline
\end{tabular}

Fuente: Elaboración propia con base en información de la Sectur, 2018. 
El programa Pueblos Mágicos conjunta una serie de localidades que comparten una problemática común que se complica con el turismo. Al respecto de la patrimonialización y banalización de espacios, no sólo por la Unesco y su Lista del Patrimonio Mundial, la autora Maria Adélia de Souza plantea un dialogo interdisciplinario, entre la geografía y las disciplinas encargadas de la conservación y restauración de los sitios patrimonializados, desde una perspectiva social, para asumir el espacio geográfico como una instancia social, en un mundo globalizado cada vez más marcado por desigualdades socio espaciales. Entendiendo este patrimonio como un conjunto de activos, derechos y obligaciones vinculados a una persona o una sociedad. Es evidente, que esto tiene implicaciones directas en las formas de vida, los usos del territorio y la constitución de lugares en el planeta, debido a las nuevas posibilidades de las tecnologías de la información, que permiten nuevas formas de manifestación de procesos políticos y culturales en el mundo (Souza, 2019).

Un claro ejemplo de esta banalización de espacios es el programa Pueblos Mágicos que ha tenido éxito a nivel nacional y se pretende internacionalizar para atraer turistas del mundo; no obstante, varios de éstos ya son visitados por turistas extranjeros desde la creación del programa, como se señala para el caso de Real de Catorce, San Luis Potosí, desde su nombramiento en 2001 (Alvarado-Sizzo y Costa, 2019), como un ejemplo evidente de patrimonialización global. La vida contemporánea se nutre por el consumo, donde uno de los productos se deriva de los aspectos de la preservación del patrimonio y del turismo.

La posibilidad de que un Pueblo Mágico pueda ser inscrito en la Lista del Patrimonio Mundial de la Unesco permeó el imaginario con el caso específico de San Miguel de Allende, Guanajuato, que trascendió a nivel nacional porque pasó de ser Pueblo Mágico a ser Patrimonio Mundial, como lo señaló en una entrevista el entonces presidente municipal Rodolfo Jurado Maycotte: "dejó de ser Pueblo Mágico para convertirse en Ciudad Patrimonio de la Humanidad de la Unesco" (W Radio, 2009). El caso de San Miguel de Allende, Guanajuato, fue posible; no obstante, porque primero, el 28 de julio de 1982, obtuvo la declaratoria como ZMH, por ser la cuna de Ignacio Allende, héroe de la independencia nacional, entre otros aspectos. Luego logró el nombramiento como Pueblo Mágico en 2001, pues fue una de las primeras $\mathrm{ZMH}$ en obtener tal denominación. Finalmente, el Comité del Patrimonio Mundial de la Unesco inscribió a San Miguel de Allende en la Lista del
Patrimonio Mundial (Conaculta-INAH, 2009), en la reunión del Comité en Quebec, Canadá, el 8 julio de 2008, y por ello salió del programa; sin embargo, sabemos que un sitio debe tener algún valor universal excepcional y cumplir cuando menos con uno de los criterios de la Convención; además, el Estado parte, es decir, el gobierno de México, debe proponer su inscripción. En este caso es claro el proceso de patrimonialización nacional y luego global de un sitio mexicano al ser legitimado por la Unesco.

El programa Pueblos Mágicos fue implementado, supuestamente en favor del desarrollo social, y se concibió para atraer inversiones y generar empleos en las localidades; sin embargo, ha provocado en la mayoría de los casos desplazamiento social y cambios en los usos del suelo; sobre todo, por el incremento de las rentas urbanas, porque los servicios y productos comienzan a dirigirse a estratos socioeconómicos más altos, que la población de menores ingresos no puede pagar. Este programa es claramente de corte neoliberal, "la gentrificación no es necesariamente un objetivo perseguido por los gobiernos, sino un fenómeno producido por este modelo (neoliberal)" (Delgadillo, 2017, pp. 195-217). Pueblos Mágicos ha ido desplazando silenciosa y paulatinamente mediante diversas presiones inmobiliarias tanto a los habitantes como a pequeños negocios familiares.

Una manera de abordar los efectos del programa Pueblos Mágicos, como se señaló en el anterior párrafo, nos la ofrecen las teorías de la gentrificación pues son una herramienta útil para el análisis de desalojos y desplazamiento que el Estado implementa, como parte de una política neoliberal en estos procesos en los centros de las ciudades de América Latina (Janoschka y Sequera, 2014). Es el caso de las ciudades históricas mexicanas con declaratoria de ZMH y/o nombramiento de Pueblos Mágicos, porque su patrimonialización ha funcionado, en la vía de los hechos, como una estrategia para cambiar la composición social de los habitantes de un territorio que también incluye la transformación de otros aspectos de la vida cotidiana.

El neoliberalismo, que en México impuso políticas de turismo sobre las de protección y conservación del patrimonio cultural urbano, ha dejado huella en varias localidades, un ejemplo que evidencia la problemática entre patrimonio y turismo lo muestra Hiernaux (2015), con el caso de Mineral de Pozos, estado de Guanajuato, cuyo decreto como ZMH fue publicado el 27 de julio de 1982 en el DOF. Luego de mostrar una minuciosa reseña histórica y el abandono posterior, después 
de las épocas de esplendor de este pueblo minero, el autor analiza los imaginarios sociales a partir de la patrimonialización de las ruinas de instalaciones mineras y del pueblo abandonado. También, enfatiza los procesos de despojo y urbanización hacia 2003, como parte de políticas gubernamentales que permitieron la presencia de empresarios y políticos nacionales que facilitaron la inversión privada en la urbanización de las inmediaciones del poblado, y en el "rescate y recuperación" de las construcciones abandonadas; con lo que, propiciaron el encarecimiento del suelo al implantarse residentes extranjeros, segundas residencias de nacionales y el turismo de amenidades, especialmente de "hoteles boutique". Todo ello, de acuerdo con el autor, se afianzó cuando Pozos fue nombrado Pueblo Mágico en 2012. El nombramiento encubrió y facilitó proyectos turísticos y residenciales que se consolidaron a partir del programa de desarrollo urbano turístico que permitió la especulación y mercantilización del suelo, con el pretexto del desarrollo turístico (Hiernaux, 2015).

Otro ejemplo contundente es el también pueblo minero Real de Catorce, en el estado de San Luis Potosí; los autores Alvarado-Sizzo y Costa (2019) explican la historia urbana de este sitio desde su origen, su apogeo productivo y su decaimiento en el siglo XX, pasando por el abandono poblacional y el regreso a lo rural para subsistir. El auge y explotación de los recursos minerales produjo varias edificaciones emblemáticas que reflejan esa época de esplendor, con obras dedicadas al culto religioso, al servicio y el ornato públicos y al uso habitacional; además, de los relacionados con la minería. Todo este patrimonio edilicio, sumado al contexto natural y rural de Real de Catorce, le permitieron ser nominado Pueblo Mágico en 2001; a pesar de contar desde la década de 1970 con un proyecto para ser declarado ZMH el decreto fue publicado hasta el 29 de noviembre de 2012; siendo ésta la única localidad que primero fue incluida en el programa turístico, y después declarada patrimonio nacional. Los autores señalan el año 2001 como el parteaguas en la patrimonialización y crecimiento significativo del turismo, porque Real de Catorce se popularizó, cuando fue escenario de dos producciones hollywoodenses, que consolidaron la imagen de un lugar donde "se ha detenido el tiempo" (Alvarado-Sizzo y Costa, 2019, pp. 1-26).

Como se ha señalado son muchas localidades pequeñas las que han logrado su inclusión en el programa Pueblos Mágicos, debido en gran medida a su relación con el entorno natural y porque muchas actividades económicas y sociales están ligadas con la producción agrícola y rural. En este sentido, podemos hablar de gentrificación en el medio rural, por lo que podemos señalar que "el programa Pueblos Mágicos fue impulsado como una política pública, donde el estado involucra la inversión privada que justifica las intervenciones urbanas en dichas localidades; así como, la introducción de comercios, y servicios para el turismo" (Hiernaux y González, 2014, pp. 55-70); asimismo, para estos autores el turismo adquiere un sentido renovado: el turista no es solamente un "visitante" que recorre espacios, pues realiza prácticas socio espaciales en un contexto ya ocupado por otros grupos sociales locales quienes tienen sus propias prácticas. En concordancia con lo anterior (Janoschka y Sequera, 2014) señalan también el cambio en la composición social de los habitantes de un territorio, que incluye la transformación de otros aspectos de la vida cotidiana.

Algunos otros ejemplos en el mismo sentido de actividades turísticas y sus efectos socio espaciales en estas localidades podemos encontrarlos en la obra Pueblos Mágicos. Una visión interdisciplinaria, que ofrece investigaciones sobre 61 de los 121 Pueblos Mágicos, abordadas desde distintas perspectivas por investigadores de diversas entidades académicas, la obra comprende tres volúmenes publicados entre 2015 y 2017 (López, Valverde, Fernández y Figueroa, 2015).

\section{Conclusiones}

Desde su creación, el programa Pueblos Mágicos fue ampliamente difundido y publicitado por lo que es conocido en todo el país; sin embargo, el público en general desconoce la existencia de las declaratorias de ZMH. El INAH de manera ininterrumpida ha cumplido su función de proponer las declaratorias al ejecutivo federal en turno; no obstante, en los últimos tres sexenios, de 2000 a 2018, la balanza entre declaratorias y nombramientos se inclinó hacia los Pueblos Mágicos.

Como se ha señalado, son varias las implicaciones socio espaciales y efectos en el patrimonio cultural urbano cuando una ZMH adquiere el nombramiento de Pueblo Mágico, y pasa a formar parte de un catálogo de destinos turísticos que todos quieren visitar, como si se tratase de un producto o mercancía cuyo objetivo fuese sólo atraer turistas en masa por un fin de semana. Uno de los efectos más notorios es la afectación a la autenticidad urbana arquitectónica; es decir, los cambios y alteraciones, tanto en el 
espacio privado como en el público. Me refiero a las intervenciones sólo en la imagen urbana de los Pueblos Mágicos; por ejemplo, la aplicación de pintura en fachadas multicolores, el agregado de tejados o pretiles para homogeneizar y dejar el sitio "bonito para la visita turística", particularmente en arquitectura patrimonial y vernácula, donde es deseable intervenir integralmente y no sólo la fachada. Lo mismo ocurre con las intervenciones en el espacio público, generalmente siempre en el centro de la localidad; por ejemplo, se repite la sustitución de empedrados antiguos por concreto estampado o por adoquines, en lugar de restaurarlos. En este sentido, es posible referir que detrás de la patrimonialización existe otro mecanismo de creación de valor, la mercantilización de lo auténtico, basada en la existencia de valores de uso puro (Frigolé, 2014).

La gentrificación también deja su huella paulatina en los Pueblos Mágicos, porque propicia desplazamiento social y de comercio tradicional al permitir cambios en los usos del suelo; además, se sobrepasa la capacidad de acogida, se pone en riesgo el significado social y la identidad cultural de los habitantes, y de cada sitio. En este sentido, el concepto gentrificación es una categoría idónea para expresar las transformaciones socio espaciales ligadas a la recualificación del espacio urbano, con la sustitución de sectores bajos por otros de mayor ingreso (Bournazou, 2017). Asimismo, es imperativo en estos casos la aplicación de los principios de la Carta internacional sobre el turismo cultural del ICOMOS para garantizar la participación de los habitantes en la toma de decisiones y beneficios de los recursos generados por el turismo; así como, designar una parte de esos ingresos para la conservación de su patrimonio cultural (ICOMOS, 1999).

El programa Pueblos Mágicos entregaba recursos federales a los ayuntamientos de las localidades con nombramiento para invertirlo en obra pública, como cableado subterráneo y mejoramiento de imagen urbana; sin embargo, por el tiempo que las administraciones tienen para ejecutar las obras, menos de tres años, muchas veces se propiciaron intervenciones carentes de un proyecto que garantizara la conservación del patrimonio cultural urbano y de la aprobación y la supervisión del INAH.

Las declaratorias federales manifiestan el compromiso del Estado mexicano para conservar el patrimonio cultural urbano de las $\mathrm{ZMH}$, incluidas las 22 que tienen nombramiento de Pueblo Mágico. Por lo que no se deben priorizar los intereses turísticos sobre el patrimonio cultural, por el contrario, éste debe ser revalorado por el turismo para aprovecharlo en beneficio de cada localidad.

De la conservación del patrimonio cultural urbano depende en gran medida el desarrollo nacional. Anteponer el atractivo turístico sobre la utilidad pública o el simbolismo y trastocar aspectos arquitectónicos, urbanos, sociales e identidad del patrimonio cultural de estos sitios, los deja a expensas de la mercantilización, por lo que se hace necesario conciliar las contradicciones entre ambas categorías: declaratorias y nombramientos. Entre un acto y otro hay varias diferencias, la más importante es que para alcanzar una declaratoria es poco común que se soliciten al INAH a petición de parte, mientras que para obtener un nombramiento las solicitudes a la Sectur son muchas. Los ayuntamientos interesados tratan de cumplir con los requisitos que el programa exige para ingresar y permanecer en el programa. En el caso de una declaratoria sólo la revocación presidencial excluiría a una localidad de la misma, y para los Pueblos Mágicos el nombramiento se retiraba, por parte de la Sectur, en caso de que el ayuntamiento incumpliera con alguno de los puntos que el programa exige.

Es necesario entender esta problemática urbana desde una perspectiva geográfica, social y económica para tener elementos culturales y sociales que permitan generar una gestión única que le dé respuesta. Los paisajes urbanos históricos mexicanos en gran medida mejorarán a partir de una buena planeación urbana; por lo que, es necesario contar con lineamientos generales de conservación urbana y controlar el turismo - que los huecos legales no permiten hacer-mediante el aprovechamiento de las leyes, acuerdos y decretos que no se han sabido o podido aplicar, para conjugar los diferentes intereses y objetivos de todos los actores involucrados en beneficio del patrimonio cultural urbano de México.

\section{Referencias bibliográficas}

Alvarado-Sizzo, I. y E. Costa. (2019). Situación geográfica turística en la era urbana y devenir campo-ciudad en América Latina. Investigaciones Geográficas, (99), 1-26. I. G. Universidad Nacional Autónoma de México. DOI: dx.doi.org/10.14350/rig.59792.

Recuperado el 21 de marzo de 2020, en: http://www.scielo.org.mx/pdf/igeo/n99/ 2448-7279-igeo-99-e59792.pdf 
Bandarin, F. y R. Van Oers. (2014). El paisaje urbano histórico. La gestión del patrimonio en un siglo urbano. (J. M. Acosta, Trad.) Madrid: Abada editores.

Becerril, M. (2009). Los principios legales de la Convención del Patrimonio Mundial. México: Instituto Nacional de Antropología e Historia.

Bournazou, E. (2017). Introducción. En E. Bournazou (Coord.), Gentrificación: miradas desde la academia y la ciudadanía (pp. 11-27). México: Facultad de ArquitecturaUniversidad Nacional Autónoma de México.

Choay, F. (2007). Alegoría del patrimonio. Barcelona: Gustavo Gili.

Conaculta-INAH (2009). El patrimonio de México y su valor universal. Sitios inscritos en la Lista del Patrimonio Mundial 2008 (3a. ed.). México: Consejo Nacional para la Cultura y las Artes-Instituto Nacional de Antropología e Historia.

Costa, E. (2014). Fundamentos de uma emergente patrimonialização global. Geografía, 39 (2), 241-256.

DOI: dx.doi.org/10.14350/rig.59593.

Recuperado el 14 de marzo de 2020, en: https://www.periodicos.rc.biblioteca.unes p.br/index.php/ageteo/issue/view/978

De Souza, M. (2019). Territorio usado, rugosidades e patrimonio cultural: ensaio geográfico sobre o espaço banal. PatryTer, 2 (4), 1-17. https://doi.org/10.26512/patryter.v2i4.26 485. Recuperado el 14 de marzo de 2020, en:

https://periodicos.unb.br/index.php/patr yter/article/view/26485

Delgadillo, V. (2015). Patrimonio urbano, turismo y gentrificación. En Delgadillo V, I. Díaz, y L. Salinas (Coords.), Perspectivas del estudio de la gentrificación en México y América Latina (pp. 113-132). México: I. G. Universidad Nacional Autónoma de Mexico.

Delgadillo, V. (2017). Plan Integral de Manejo del Centro Histórico de la Ciudad de México, un instrumento de gestión neoliberal. En Bournazou, E., Gentrificación: miradas desde la académia y la ciudadanía (pp. 195-217). México: Facultad de ArquitecturaUniversidad Nacional Autónoma de México.

Díaz-Berrio, S. (2007). Protección y rehabilitación del patrimonio cultural urbano. México: Universidad Autónoma Metropolitana, Xochimilco.
DOF. (1939, febrero 3). Ley Orgánica del Instituto Nacional de Antropología e Historia. Diario Oficial de la Federación. Recuperado el 5 de noviembre de 2020, en: http://www.diputados.gob.mx/LeyesBibli $\mathrm{o} / \mathrm{pdf} / 170 \quad 171215 . \mathrm{pdf}$

DOF. (1972, mayo 6). Ley Federal sobre Monumentos y Zonas Arqueológicos, Artísticos e Históricos. Diario Oficial de la Federación. Recuperado el 20 de febrero de 2019,

en: https://www.dof.gob.mx/nota to imagen fs.php? codnota $=4808187 \&$ fecha $=06 / 05$ $\angle 1972 \&$ cod diario $=206950$

DOF. (1994, agosto 4). Ley Federal de Procedimiento Administrativo. Diario Oficial de la Federación. Recuperado el 10 de febrero de 2020, en: https://www.dof.gob.mx/nota to imagen fs.php? codnota $=4724573 \&$ fecha $=04 / 08$ $\angle 1994 \&$ cod diario $=203647$

DOF. (2009, junio 17). Ley General de Turismo. Recuperado el 21 de febrero de 2019, en: http://www.dof.gob.mx/nota detalle.php ?codigo $=5094830 \&$ fecha $=17 / 06 / 2009$

DOF. (2013, mayo 20). Plan Nacional de Desarrollo. México. Recuperado el 15 de febrero de 2020, en: http://www.dof.gob.mx/nota detalle.php ?codigo $=5299465 \&$ fecha $=20 / 05 / 2013$

DOF. (2014, septiembre 26). Acuerdo por el que se establecen los lineamientos generales para la incorporación y permanencia al Programa Pueblos Mágicos. Diario Oficial de la Federación. Recuperado el 25 de agosto de 2019, en: https://www.dof.gob.mx/nota detalle.ph p? codigo $=5361690 \&$ fech $a=26 / 09 / 2014$

DOF. (2016, noviembre 28). Ley General de Asentamientos Humanos, Ordenamiento Territorial y Desarrollo Urbano y se reforma el Artículo 3o. de la Ley de Planeación. Diario Oficial de la Federación. Recuperado el 20 de julio de 2019, en: https://www.dof.gob.mx/nota detalle.ph p? codigo $=5462755 \&$ fech $a=28 / 11 / 2016$ 
DOF. (2018, julio 26). Acuerdo por el que se modifica el Anexo Único, Manual de la Manifestación de Impacto Regulatorio del diverso por el que se fijan plazos para que la Comisión Federal de Mejora Regulatoria resuelva sobre anteproyectos y se da a conocer el Manual de la Manifestación de Impacto Regulatorio. Diario Oficial de la Federación. Recuperado el 21 de marzo de 2020,

en: http://www.dof.gob.mx/nota detalle.php ? codigo $=5466670 \&$ fech $a=22 / 12 / 2016$

El Universal. (2018, diciembre 21). Recuperado el 20 de enero de 2020, en: https://www.eluniversal.com.mx/nacion/ sociedad/dejan-sin-recursos-121-pueblosmagicos-de-mexico

Frigolé, J. (2014). Patrimonialización y mercantilización de lo auténtico. En X. Roigé, J., Frigolé, J. y C. del Mármol, Construyendo el patrimonio cultural y natural. Parques, museos y patrimonio rural (pp. 31-45). Valencia: Germania. Recuperado el 21 de marzo de 2020, en: https://www.researchgate.net/publication $\angle 279804514$ Construyendo el patrimonio cultural y natural Parques museos y $\mathrm{p}$ atrimonio rural

Hardoy, J. y M. Gutman. (1992). El impacto de la urbanización en los Centros Históricos de Iberoamérica. (Unesco, Ed.) Madrid: MAPFRE.

Harvey, D. (2007). Breve historia del neoliberalismo. Madrid: Akal.

Hiernaux, D. (2015). Mineral de Pozos, Guanajuato. Entre imaginarios, invento del patrimonio, expoliación y conflictos. En López, L., C. Valverde, A. Fernández y M. Figueroa, Pueblos Mágicos. Una visión interdisciplinaria (pp. 319-340). México: Universidad Autónoma Metropolitana y Facultad de Arquitectura-Universidad Nacional Autónoma de México.

Hiernaux, D. y C. González. (2014). Turismo y gentrificación: pistas teóricas sobre una articulación. En: Revista de Geografía Norte Grande (58) (pp. 55-70). ISSN: 0379-8682. Recuperado el 14 de marzo de 2020, en: https://www.redalyc.org/pdf/300/30031 739004.pdf

Icomos. (1999). Carta Internacional sobre Turismo Cultural. La Gestión del Turismo en los sitios con Patrimonio Significativo. Recuperado el 30 de noviembre 2019 en: https://www.icomos.org/charters/touris m sp.pdf
López, L., C. Valverde, A. Fernández y M. Figueroa. (2015). Pueblos Mágicos. Una visión interdisciplinaria (Vols. I, II y III). México: Universidad Autónoma Metropolitana y Facultad de ArquitecturaUniversidad Nacional Autónoma de México.

Madrid, F. (2016). Reflexiones sobre la concepción estratégica de programa pueblos mágicos y su evolución en el tiempo. En F. Madrid (Coord.), Pueblos Mágicos: Aciertos y retos de una iniciativa de política pública en turismo (Vol. I) (pp. 45-66). México: Limusa.

Melé, P. (2006). La producción del patrimonio urbano. México: Centro de Investigaciones y Estudios Superiores en Antropología Social.

Janoschka, M. y J. Sequera. (2014). Procesos de gentrificación y desplazamiento en América Latina, una perspectiva comparativista. En Michellini, J. (Ed.), Desafios metropolitanos. Un diálogo entre Europa y América Latina (pp. 82-104). Madrid: Catarata.

Ortiz, J. (1994). Ciudades coloniales mexicanas. México: Secretaría de Turismo.

Sectur. (2018). Comunicado 84. Recuperado el 15 de febrero de 2019 en: https://www.gob.mx/sectur/prensa/mexi co-sexto-lugar-del-ranking-mundial-enarribo-de-turistas-internacionalesconfirma-omt

W Radio. (2009, marzo 5). Pasa San Miguel de Allende de Pueblo Mágico a Patrimonio de Humanidad. Recuperado el 21 de marzo de 2020 en: http://wradio.com.mx/radio/2009/03/05 /sociedad/1236286380 773203.html

\section{Notas}

i Artículo $2^{\circ}$ fracción XI.- Proponer al Ejecutivo Federal las declaratorias de zonas y monumentos arqueológicos e históricos y de restos paleontológicos, sin perjuicio de la facultad del ejecutivo para expedirlas directamente. Ley Orgánica del Instituto Nacional de Antropología e Historia. Reformada mediante decreto el 20 de diciembre de 1985 y publicada en el DOF. Esta fracción fue reformada el 17 de diciembre de 2015, por lo que ahora las declaratorias se proponen el secretario de Cultura, sin prejuicio de la facultad del ejecutivo para expedirlas directamente. En vía de los hechos hasta el 2019 todas las declaratorias 
han contado con la firma del presidente de la república en turno.

ii Estos Listados de Monumentos Históricos corresponden a Tlayacapan, Morelos, y Texcoco de Mora, Estado de México; a diferencia de una declaratoria de Zona de Monumentos Históricos, esos decretos no tienen un perímetro de protección descrito en la declaratoria publicada.

iii En el actual sexenio de Andrés Manuel López Obrador (2018-2024) se publicó en el Diario Oficial de la Federación, el 13 de marzo de 2019 la declaratoria de Zona de Monumentos Históricos en Tihosuco, municipio de Carrillo Puerto, estado de Quintana Roo, siendo la zona número 60. Al estar fuera del periodo de estudio indicado no se muestra en la Tabla 1 ni en el Mapa 1.

iv El centro Histórico de la ciudad de Zacatecas logró su inscripción en 1993 a pesar de no contar con la declaratoria federal como Zona de Monumentos Históricos.

v Nombramiento: Acción que realiza la Secretaría de Turismo Federal, con el respaldo de documentos técnicos, para designar a una localidad Pueblo Mágico, la cual acredita el cumplimiento de los requisitos de incorporación o permanencia al Programa Pueblos Mágicos.

vi El Grupo de Evaluación se conformará con los siguientes integrantes quienes tendrán voz y voto: Presidente, que será el Titular de la Secretaría de Turismo; Secretario Técnico, que será el Director General de Gestión de Destinos; Vocales, que serán los titulares de: Subsecretaría de Innovación y Desarrollo Turístico; Subsecretaría de Planeación y Política Turística; Subsecretaría de Calidad y Regulación; Consejo de Promoción Turística de México (CPTM), y Fondo Nacional de Fomento al Turismo (Fonatur).

vii El Grupo de Evaluación y Seguimiento Pueblos Mágicos está integrado por los titulares de: Secretaría de Turismo (Sectur); Secretaría de Educación Pública (SEP); Secretaría de Desarrollo Social (Sedesol); Secretaría del Trabajo y Previsión Social (STyPS); Secretaría de Economía (SE); Secretaría de Medio Ambiente y Recursos Naturales (Semarnat); Fondo Nacional para el Fomento de las Artesanías (Fonart); Consejo Nacional para la Cultura y las Artes (Conaculta); Banco Nacional de Obras y Servicios (Banobras); Comisión Federal de Electricidad (CFE); Comisión Nacional del Agua (Conagua), e Instituto Nacional de Antropología e Historia (INAH). 